\title{
Transferring Handmaids: Iconography, Adaptation, and Intermediality
}

Kate Newell

\section{Contents}

2.1 Introduction.

2.2 Intermediality, Iconography, and Transfer.

2.3 Mediation in The Handmaid's Tale (1985)

2.4 The Handmaid: Establishing a Network of Iconography.

2.5 Print-Based Movement: Illustration and Graphic Novel.

2.6 Motion-Based Transfer.

2.7 Transfer and Networks.

\subsection{INTRODUCTION}

All around us, depictions of red-cloaked, white-bonneted female silhouettes proliferate. An image of the forty red topiaries that lined the east colonnade of the White House in the 2018 Christmas season, edited to appear topped with white "Handmaid" bonnets, went viral on Twitter in November 2018. A June 9, 2019 Associated Press article entitled

K. Newell $(\bowtie)$

Savannah College of Art and Design, Savannah, GA, USA

e-mail: knewell@scad.edu

(C) The Author(s) 2021

L. Elleström (ed.), Beyond Media Borders, Volume 2, https://doi.org/10.1007/978-3-030-49683-8_2 
"Scientists feel chill of crackdown on research" is accompanied by a May 23, 2017 photograph of women donning red cloaks and white bonnets at a protest against Texas SB8, a bill which bans second trimester abortion, and requires that fetal remains be buried or cremated (Neergaard et al. 2019). A lingerie website stocked a "Brave Red Maiden" costume "featuring a red mini dress, a matching cloak with attached hood, and a white bonnet headpiece" (Gupta 2018). ${ }^{1}$

While many viewers recognize this iconography from Margaret Atwood's novel, The Handmaid's Tale (1985) or the Hulu series (2017-) of the same name, a recognition of the source does not explain how the red cloak and white bonnet have come to signify in contexts as diverse as a topiary display, threats to scientific research, and lingerie. In the thirtyfive years since its publication, The Handmaid's Tale has been adapted numerous times in a range of media. Reasons for its longevity are many: the novel's popularity and status as a classic work in dystopian literature make it ripe for adaptation, as does the fact that it has already been adapted, as works that have been adapted one or more times seem to be prime candidates for future adaptation. Another, perhaps more telling reason behind the continued adaptation is a general feeling that the novel's themes reflect the political dis-ease of a particular moment. Conversations related to any adaptation of The Handmaid's Tale, regardless of the decade, are likely to mention the contemporary political climate in the United States, and elsewhere. ${ }^{2}$ This sense of sustained relevance means that The Handmaid's Tale is almost always read through and against broad contextual lenses at the same time that the novel becomes the point of reference for that context.

This essay examines the intermedial transfer of Handmaid iconography across platforms and contexts, and the mechanisms that facilitate such movement. I begin with a consideration of the intermedial network established within Atwood's novel to show that, even prior to adaptation, the Handmaid is understood as a product of intermedial transfer. I next survey the movement of Handmaid iconography in a variety of seemingly static print-based and dynamic motion-based media, and then turn to articulations of Handmaid iconography in more generalized spheres. The image of the Handmaid transfers through processes of adaptation that interpret visual markers in distinct modalities, each of which emphasizes particular traits or characteristics over others. The emphasis or disclosure that characterizes each iteration is accompanied by concealment; that is, as an adaptation foregrounds a particular modality, it simultaneously represses another. In the context of The Handmaid's Tale, the tension between 
disclosing and concealing, between visibility and invisibility operates thematically and in terms of its foregrounded media.

\subsection{InTERMEDIALITY, ICONOGRAPHy, AND Transfer}

There are many ways to think about intermediality, iconography, and transfer. My own view of intermediality aligns with that described by Irina O. Rajewsky in her contribution to the essay collection Media Borders, Multimodality, and Intermodality: "Generally speaking, and according to common understanding, 'intermediality' refers to relations between media, to medial interactions and interferences. Hence, 'intermediality' can be said to serve first and foremost as a flexible generic term 'that can be applied, in a broad sense, to any phenomenon involving more than one medium' and thus any phenomenon that-as indicated by the prefix inter - in some way takes place between media. Accordingly, the crossing of media borders has been defined as a founding category of intermediality" (Rajewsky 2010: 51-52). ${ }^{3}$ Rajewsky proposes viewing borders as sites of possibility, "as enabling structures, as spaces in which we can test and experiment with a plethora of different strategies" (65). The broadness of this conceptualization, which I find welcome, may frustrate others who approach intermediality more narrowly or who would prefer a more circumscribed set of terms that delineate media borders and avenues of "crossing." Yet, as Rajewsky, Lars Elleström, and other contributors to this volume illuminate, such borders, while useful theoretically, are always constructed and perceptual. That is, no material 'border" exists between, say, the animated and live-action segments of a particular film, yet audiences perceive aesthetic differences, and articulate that difference in terms of juncture and border crossing.

Throughout this essay, I refer to the movement or transfer of iconography from one media product to another. Here, I use "iconography" to refer to a dynamic and fluid collection of visual symbolic information that signifies to perceivers a distinct "message" - be that message a particular cultural object or other form of communication. By "transfer," I mean the generalized perception that messaging associated with one place "moves" to another. ${ }^{4}$ That which is transferred may be iconography or theme or tone or narrative or character or compositional principle, or any number of identifiable aspects. The perception that transfer has occurred does not mean that the thing no longer exists in the previous location (or previous locations before that). My concept of transfer is informed by a model of 
communication put forward by Elleström in "The modalities of media II: An expanded model for understanding intermedial relations" (2020). Elleström identifies "three indispensable and interconnected entities" necessary for communication to occur between a "producer's mind" and a "perceiver's mind" (2020: 10, 12): "1. Something being transferred"; "2. Two separate places between which the transfer occurs"; "3. An intermediate stage that makes the transfer possible" (2020: 10).

All media products are communicated by way of their materiality, and, likewise, the perception of transfer manifests in materiality. Elleström's model identifies "four kinds of basic traits," or "media modalities"; these include the material, spatiotemporal, sensorial, and semiotic modalities. All media products are realized through some materiality (e.g., flat, raised, solid), and experienced spatiotemporally (e.g., two-dimensional, threedimensional, sequential, non-sequential) and sensorially (e.g., audial, visual). The semiotic modality is "derived from" the other three modalities. That is, the perceiver takes in material, spatiotemporal, and sensorial information and interprets that information as signifying (2020: 20). Important to the process of communication is the manner by which perceivers understand their particular experience of a given message as compared to and within the context of previous perceptions and communications-what Charles S. Peirce called "collateral experience" (Elleström 2020: 26-27). In the course of examining the movement of Handmaid iconography, I show how each adaptation foregrounds certain modalities to lead perceivers toward particular interpretations of the communication transfer.

\subsection{Mediation in The Handmaid's Tale (1985)}

"What's fascinating about the legacy of The Handmaid's Tale," Natalie Zutter writes, "is how it's spread to almost every medium: reimagined on stage and screen, buzzing on the airwaves and between your ears, inked earnestly onto skin and snarkily onto protest signs, embodied in real bodies through viral marketing and political action. [...] you can see Offred's story from tech conferences to the Senate floor" (2017). Zutter's verb choices_-"reimagined," "buzzing," "inked," "embodied"—identify multiple avenues of mediation that point both to communication transfer (e.g., how particular messages are produced, transferred, and perceived) and medial transfer (e.g., how The Handmaid's Tale is adapted from novel to television, radio, and commercial and political arenas). This aspect of 
The Handmaid's Tale's legacy is not as surprising as it might seem at first glance. Atwood incorporates into the novel numerous medial references, both within the "tale" and as an organizing tool for the narrative conceit. Such moments indicate a keen awareness of how media and mediation function in concert to construct and convey meaning, as well as how shifts in media impact perception. The "Historical Notes" section, which appears at the end of the "tale" proper, purports to provide "a partial transcript" of a "live" event-the 2195 conference proceedings of the Twelfth Symposium on Gileadean Studies, in which Professor James Darcy Pieixoto conveys orally the context of the transcribed "The Handmaid's Tale" in a talk entitled, "Problems of Authentication in Reference to The Handmaid's Tale" (Atwood 1985: 312). In this turn, readers realize the conceit: the text that they thought they had been reading as a fictional novel is presented as both an excerpt from conference proceedings as well as the supplement on which those proceedings are based.

Professor Pieixoto's comments alert his audience to the elaborate network of transmedial transfer that has informed his presentation. The Handmaid's "tale" had been invisible, recorded onto some thirty cassette tapes over existent musical recordings. At the time of the discovery, cassette tape technology had long been obsolete. However, Professor Pieixoto and his colleague, Professor Wade, have "with the aid of [their] excellent resident antiquarian technician, reconstructed a machine capable of playing such tapes" (313). For Pieixoto and Wade, the concern in transferring an oral account to audio recording and then to transcript and then to oral presentation rests in the authenticity of the medial relationships and crossings. Pieixoto states that "we were assured by the experts who examined [the tapes] that the physical objects themselves are genuine. Certainly, the recording itself, that is, the superimposition of voice upon music tape, could not have been done within the past hundred and fifty years" (315). For these scholars, authenticity of medium and authenticity of narrative are yoked-the narrative's authenticity comes into being through the processes of adaptation and transmediation that allow the narrative to be communicated. Visibility and invisibility factor into their establishment and assessment of authenticity in that the superimposition of one media type (oral speech) on another (music) results in the necessary concealment of one message to reveal another.

Atwood prepares her readers for such challenges of mediation within the "tale" proper. We know, for example, that the narrator's job "in the time before," prior to the instatement of the government of Gilead, was in 
a library, "transferring books to computer discs, to cut down on storage space and replacement costs, they said." The narrator relates that, "After the books were transferred they were supposed to go to the shredder, but sometimes I took them home with me. I liked the feel of them, and the look" (182). Here, the act of transfer renders one technology (print, in this case) obsolete; once content is transferred, the form is destroyed. The narrator, however, appears less interested in the content or semiotic value of the media product, and, instead, fetishizes its sensorial and material qualities - she "like[s] the feel of them, and the look." The narrator serves as the intermediate stage in the communication process-she facilitates the movement of communication from one place to another, and can also redirect that communication. In bringing a book home, she initiates a new communication and expands the intermedial network. The hypothetical book now exists in the library's records of material objects, as content transferred to disc, and as an aesthetic object in the narrator's home. The book has not abandoned any of these communication points, but exists in all simultaneously.

While the verb "transfer" suggests a seamless activity, a "move from one place to another," distinctions in definitions of transfer highlight a process that is considerably more fraught. Transfer means to "copy (data, music, etc.) from one medium or device to another." Transfer can also mean, "make over the possession of (property, a right, or a responsibility) to someone else" (Transfer 2019). Each of these definitions signifies differently in The Handmaid's Tale, particularly as the narrator herself experiences "transfer"-from freedom to bondage, from the Rachel and Leah Re-education Center (Red Center) to an assignment as a Handmaid, from the home of one Commander to that of another, from knowing to unknowing. Each of these definitions signifies differently in The Handmaid's Tale's adaptation history, as well. Much in the way that the transfer of speech to cassette and of recording to paper involves shifts in medial interface and reframing of what is seen and emphasized, transfer of, say, a novel from its physical, dimensional book materiality to a physical, dimensional disc materiality involves a reframing - a reframing of how that novel is read (paper vs. screen, page turn vs. scroll) and understood as a sensory object (smell, touch) — and a tacit understanding that all materialities are prone to obsolescence. 


\subsection{The Handmaid: Establishing a Network OF ICONOGRAPHY}

Early in the novel, Atwood's narrator describes the features of her Handmaid uniform:

I get up out of the chair, advance my feet into the sunlight, in their red shoes, flat-heeled to save the spine and not for dancing. The red gloves are lying on the bed. I pick them up, pull them onto my hands, finger by finger. Everything except the wings around my face is red: the colour of blood, which defines us. The skirt is ankle-length, full, gathered to a flat yoke that extends over the breasts, the sleeves are full. The white wings too are prescribed issue; they are to keep us from seeing, but also from being seen. $(1985: 18)^{5}$

This description demonstrates to readers the boundaries between "Handmaid" and "not Handmaid," as well as that between "individual" and "Handmaid" through statements that establish both the narrator's awareness of her subject position (i.e., "I") and the object position of Handmaid (e.g., "their red shoes," "the breasts"). The specifics of the uniform cannot be separated from its task of creating distanciation between self and role, and of rendering Handmaids both highly visible and invisible. As the narrator, called Offred within Gilead, learns during her reeducation process at the Red Center, "[m]odesty is invisibility [...]. To be seen - to be seen - is to be [...] penetrated" (39). The paradox in this statement is that the Handmaid's job is to be penetrated, monthly, by a Gilead Commander, in the context of the government-ordained Ceremony. The danger is in being "seen" as an individual, in a perceiver acknowledging the boundary between Handmaid and individual. "Modesty," as defined within Gilead, protects that boundary. The uniform renders all Handmaids more or less anonymous visual equivalents (as reinforced in the narrator's blurring of plural/singular usage in describing her movements with a fellow Handmaid: "Doubled, I walk the street" [33]). The red uniform transforms the women who wear it into symbols, both of lifebringing possibilities, and of sexual threat and promiscuity. In explaining a character's coldness toward her, the narrator explains, "the frown isn't personal: it's the red dress she disapproves of, and what it stands for" (19). There are certain exceptions to the Handmaids' anonymity, of course. Pregnant Handmaids are made visible, individualized by their swollen 
bellies, which distend the front of the red dress, altering its shape. Handmaids are also visible to each other: they see each other as distinct women wearing the uniform, rather than as "Handmaid." Such instances of recognition draw attention to the constructed nature of these individual and thematic borders.

Atwood's descriptions of the uniform are not quite ekphrastic, but offer enough detail to convey to readers a clear image of the uniform, while remaining general enough to invite flexibility in interpretation. Fred Marcellino's jacket illustration for the first American edition of The Handmaid's Tale, the 1986 Jonathan Cape edition, marks the first transfer of the iconic Handmaid uniform from written, verbal description to a twodimensional visual illustration, materialized through color, shape, line, typography, and other attributes of visual design. Marcellino's illustration depicts two Handmaids walking along a tall, gray brick wall. The emphasis is on the vivid red cloak and distinctive winged bonnet. The image's "bird's eye" perspective and juxtaposition of the Handmaids against the insurmountable wall evoke the dystopic society of the city of Gilead imagined in Atwood's novel, as does the anonymity of the figures. Even here, though, the image explores the boundary between the individual and the collective. The Handmaids are slightly staggered in the illustration, one moving away from the other, who has turned to look behind her-a gesture that imbues the image with a sense of expectation, and suggests subtly differences in motivations of individual Handmaids. The particular moment singled out by Marcellino is not based on a specific moment from Atwood's novel, but appears to be a generalized summation of the novel's numerous scenes of walking and looking. The particular shape and color saturation of the Handmaids' cloaks, as well as the upturn of the wings on the white headdress align with the narrator's description, but are also the product of Marcellino's transfer of visual verbal description into visual iconic signifiers.

Marcellino's interpretation initiates a method of visually articulating the Handmaid in book jacket design. A tour of The Handmaid's Tale book covers shows Marcellino's iconography transferring from edition to edition through a repetition of basic thematic and visual coding. For example, a 1998 McClelland and Stewart edition likewise features a tall gray brick wall, curving at roughly the same arc as that in Marcellino's image, and adopts also a bird's eye perspective, but depicts the Handmaid abstractly. The center of the image features a piece of red cloth blowing in the wind, bent into the shape of a Handmaid's cloak. The effect, then, is 
that of an escape, of the Handmaid flying up and over the wall. Other examples include the 1995 Virago Press cover, which features two Handmaids walking along a low wall and row of tall, spike-formed topiaries. The women are "doubled," to borrow Atwood's narrator's description, and walk with heads bent and baskets clasped.

As the iconography of the Handmaid transfers from edition to edition, the effort to imbue it with secondary symbolism becomes evident, particularly symbolism that underscores an aspect of the Handmaids' oppression (such as an inability to speak, as is emphasized in the cover of the 1986 Seal Books edition, which depicts a Handmaid with her lips bound by metal rings) or that suggests freedom. For example, the impressionistic quality of a 1996 Vintage, alternative paperback edition cover obscures the Handmaid's identity, while the saturation of red heightens the figure's visibility. The warm color palette coupled with the modeling technique suggest a melting of the Handmaid's face-alluding both to her anonymity (one Handmaid "melts" into the next), as well as the violence suffered by Handmaids at the will of the Aunts and others. A Vintage cover for a 2007 edition depicts the Handmaid in silhouette, kneeling before a fruit tree, staring upward beseechingly. Her gloved hands contort into a shape reminiscent of shadow-cast birds, and two white birds fly from her torsovisual extensions of the white bonnet. This cover incorporates into its design a crescent moon shape associated with the Red Center as well as the biohazard symbol, thus alluding to both the Handmaids' role in propagation and the punishment for women who "fail" at that role. The tree is heavy with pome fruit, underscoring the Handmaid's reproductive potential, though three pieces have fallen to the ground, suggesting unrealized opportunities.

While several covers focus on the singular Handmaid, others strive to represent graphically the uniformity of the Handmaids. The 2010 Vintage Classics edition, for example, presents a row of faceless, identical screenprinted Handmaids, reminiscent of mannequins or robots, that rare books' specialist Rebecca Romney compares to Doctor Who's Cybermen (2017). The 2017 Vintage edition designed by Suzanne Dean, featuring an illustration by Noma Bar, represents the Handmaid graphically on the front cover, signaling the Handmaid through the outline of a full red dress and white bonnet, and, again, on the back cover, through a keyhole-shaped representation of a Handmaid, which is then repeated in a pattern in the edition's front and end papers. A 2015 translated Georgian edition likewise utilizes the familiar graphic signification of the Handmaid via the 
silhouette of the red dress and white bonnet, and incorporates doubled figures against a gray wall. However, the doubling is of a Handmaid and a Wife, rather than two Handmaids. The silhouette of the wife appears behind the Handmaid, signified by blue dress and short veil. She holds a baby, coded red, that remains attached to the Handmaid via the umbilical cord, also red. The brick wall is incorporated as the shadow cast by the Handmaid, and her figure is visually segmented, divided at the chest and waist and mid-skirt. Through visual echoing, this image highlights the distinct functions of the Handmaids and the wives, while simultaneously alluding to the uniformity of those roles.

If we think of a book cover as offering a visual shorthand of a book's most essential information, the continued repetition and reinterpretation of the red cloak and white bonnet reinforces these features as essential signifiers of both the figure of Handmaid and The Handmaid's Tale. As I have discussed elsewhere, the repetition of specific iconography through successive adaptations across multiple media and platforms prioritizes that iconography as essential to and as a visual equivalent of the media object being adapted (Newell 2017). Rather than grant the Handmaid a discernable identity, the majority of book covers reinforce the anonymity of the Handmaid and, in so doing, establish in visual terms the condition of the uniform described by Atwood's narrator-to render the Handmaid both unseen and highly visible. As the image of the Handmaid transfers from edition to edition, the iconography of the costume gains semiotic weight. The visual iconic characteristics that emerge from the book covers initiate and reflect characteristics central to adaptations of The Handmaid's Tale in other media, including other print-based formats such as illustrated novels and graphic novels.

\subsection{Print-Based Movement: Illustration aNd Graphic Novel}

Book covers, book illustrations, and graphic novels share similar medial properties in that both are heavily semiotic and apprehended as twodimensional, flat surfaces and they can share similar compositional and technical features and concerns, though they differ in degrees of iconicity and spatial-temporality. Book cover designs, as we have seen, are highly iconic and non-sequential-that is, they attempt to distill a book's themes and tone into a single image, or may function as a "teaser," a hint to spark 
readers' curiosity about a book's contents. Book illustrations, on the other hand, typically adapt specific moments from a work, and invite readers to consider their semiotic import more directly in concert with the prose. We might think of the majority of book illustrations, particularly those published by major publishing houses and geared toward a mainstream market, as offering a limited sequentiality, in that most depict a succession of scenes from a novel that, when pieced together, convey an intentional trajectory or other system of cohesion. Graphic novels are fully sequential in that they communicate content visually through a series of intentionally linked visuals and frames. I now turn to consider the transfer of Handmaid iconography in Anna and Elena Balbusso's illustrations for the 2012 Folio Society edition of The Handmaid's Tale and Renée Nault's 2019 graphic novel adaptation, The Handmaid's Tale.

The Balbussos utilize the established iconography of the red cloak and white bonnet, and explore, through composition and pictorial emphasis, the various significations of the uniform. The Balbussos transfer the color coding and primacy of the Handmaid from previous iterations through, they explain, the stylistic lenses of "Futurism, Russian Constructivism and fascist-period design" - styles that add a layer of emotional detachment and impersonalization to the Handmaid iconography and subtly underscore the novel's social and political tensions (The Handmaid's Tale 2019). Much like the 2010 Vintage cover design that presents a row of identical screen-printed Handmaid uniforms, the Balbusso cover focuses on the uniform: the Handmaid figure is depersonalized, rendered as a mannequin. Four hands are positioned on the body of the mannequin as well as entering into the seemingly hollow lower-half of the torso, which symbolizes the "empty vessel" to which Handmaids are expected to aspire. The putty-colored rectangle framing the figure is suggestive of a book cover"the Handmaid's Tale" within The Handmaid's Tale—but its canting likewise evokes the imbalance of the Handmaid within her environment. In keeping with the novel's themes and those of other visual interpretations, this suite of six illustrations and a frontispiece explores tensions between Handmaids' invisibility and heightened visibility. The Balbussos render figures within Gilead uniformly, in a manner that reinforces the depersonalization of this stratified society. All Handmaids, Marthas, Wives, daughters, Guardians, and so on look alike and are rarely distinguished visually. Yet the moments that the Balbussos select to adapt trend toward the personal or interpersonal. In this way, they draw attention to the 
oppressiveness of Gileadean frameworks and explore tensions between concealing and revealing characters' "true" selves in opposition to that façade.

Illustrations have the ability to direct vision, to render visible aspects of a narrative that might be downplayed by a writer or concealed intentionally. Handmaids are fetishized throughout Atwood's novel for all they represent-fertility, sexuality, hegemonic power structures, and so on. The Folio Society edition includes an illustration of the narrator's visit to the doctor's office, titled "I take off my clothes, behind the screen, and leave them folded on the chair." This image depicts the narrator behind a red accordion screen in the doctor's office, unclothed save for her white bonnet and red stockings. This image is challenging in its positioning of the viewer and its messaging regarding the Offred. The novel makes clear that Handmaids remain clothed at all times, and that, even during the Ceremony, the body is still largely covered to help dissociate desire and other emotions from the act, to keep the Handmaid from being "penetrated." Seen in the context of the suite's emphasis on uniformity, this image may provide a rare glimpse of individuality - the person distinct from the uniform. As the Balbusso Twins explain in an interview with Porter Anderson for Publishing Perspectives, "The Handmaids seem clones. Their faces are anonymous, they're women emptied of their personalities, they've lost their identity [...]. When the Handmaid takes off her red uniform, the body re-emerges with its carnality and identity" (Anderson 2017). Yet the image also spectacularizes Offred through positioning and framing: the viewer is invited to see behind the privacy screen and to observe Offred in a private moment of adjusting her stockings-a gesture fetishized in visual culture.

As is the case with many illustrated novels, the Folio Society's illustrations are juxtaposed against prose different from their ostensible subjecta circumstance that invites and facilitates significations and thematic reflections otherwise unavailable. Within the Folio edition, "I take off my clothes" is juxtaposed not against the scene in the doctor's office, but against that in which the narrator is given a bath to prepare for the Ceremony: "I take off the rest of the clothes, the overdress, the white shift and petticoat, the red stockings, the loose cotton pantaloons." The narrator comments that, "My nakedness is strange to me already. My body seems outdated. Did I really wear bathing suits, at the beach? I did, without thought, among men, without caring that my legs, my arms, my thighs and back were on display, could be seen. Shameful, immodest" 
(Atwood 2012: 62). These two moments of undressing-for the doctor and for the bath-evoke in Offred feelings of alienation and distanciation, of heightened visibility and objectification as they precede instances of physical violation - that of the doctor's exam (and proposition of sex) and that of the Ceremony. The narrator states: "I avoid looking down at my body, not so much because it's shameful or immodest but because I don't want to see it. I don't want to look at something that determines me so completely" (63). The Balbusso image, then, invites the reader to reflect on an aspect of Offred that she, herself, avoids. That the body visible in this image is so distinct from the uniformed body presented in other illustrations may invite readers to also feel the strangeness of Offred's nakedness, and to reflect on which-uniform or individual-is the more determining or determined body. At a basic level, however, the image invites the reader to objectify Offred, to view her as a body. The viewer's vision is thus aligned with that of Gilead's dominant power structure, but differently - she is presented to us in posture that is coded openly as private and sexualized, whereas, within Gilead, she is coded as public and not sexualized.

In 2019, The Handmaid's Tale was adapted into a graphic novel by Renée Nault. Though the materiality of illustrated novels and graphic novels is similar, differences in compositional arrangement and in the proportion of word and images cause them to be perceived as distinct media. Commonly, the ratio of words to images in illustrated novels favors words, whereas graphic novels emphasize images, and tend to use the combination of words and images to convey meaning. Nault utilizes the iconography of the Handmaid uniform to explore thematic tensions between Handmaids' visibility and invisibility, often to dramatic effect through her play with proportion, color saturation, and other graphic devices. The compositional conventions of the graphic novel allow the uniform to appear as "in motion"-moving through frames-and this movement increases the range of significations, as, for example, in the scene of the Particicution, Gilead's communal execution event, which unfolds in a series of increasingly sharp and skewed panes in which the crowd of Handmaids blurs into a mob and the red of their cloaks becomes indistinguishable from the red used to convey their rage and the blood of the victim. Nault uses the uniform symbolically, depicting it as blending into or standing out from the background to establish or reinforce themes or tensions. Nault's interpretation draws from the color the stratification of Gilead society, and she describes Gilead itself as a "sort of a designer's 
dream because everything is colour-coded already and you just sort of have to guide the viewer with the symbols that already exist" (Dundas 2019). In approaching Atwood's novel, Nault explains to Shondaland's Madeleine Deliee that "the comic format complements both the narrator's perspective-which reflects jumps in time, memory, and thoughtand the story's frequent overlapping of reality and fantasy" (Deliee 2019). Nault hand-painted each page using watercolor, and selected distinct palettes to convey setting and time: flashbacks to "the time before" are depicted through a full range of color that "evok[e] what we see every day, and a more normal time," whereas scenes in Gilead are depicted through a juxtaposition of muted backgrounds and high saturation, such as the vivid red, green, and blue of the Handmaids', wives', and Marthas' uniforms (Dundas 2019).

Nault employs compositional arrangements familiar from previous visual iterations of The Handmaid's Tale, as is evident in the striking twopage spread of the narrator and her shopping partner walking along the Wall, reminiscent of Marcellino's cover illustration. As is the case in Marcellino's design, the wall dominates both the composition and the Handmaids. The two women are indistinguishable, and identifiable only by their white bonnets, red uniforms, and shopping baskets. In Marcellino, the haunting quality of the composition is heightened by the Handmaid looking behind her at an unknown beyond the frame, whereas Nault's depicts both Handmaids moving forward toward an explicit horror: six figures hanging from the gallows-the images of fetuses on their neck placards identifying them as doctors.

Given the nature of the graphic novel, one could say that the iconography of the Handmaid's uniform is reinforced in each panel that features a Handmaid. Nault, however, devotes several panels to Offred donning the Handmaid uniform at the novel's outset—slipping into the shoes, pulling on the gloves, adjusting the white wings, holding the shopping basket. As is the case in other adaptations, she extends this iconography to additional significations. Nault organizes the first page of "II: Shopping" into two horizontally oriented panels both of which depict the narrator's red shoes poised at the edge of the red circular rug of her bedroom in the Commander's house from two distinct perspectives. The top panel offers a bird's eye view of much of the bedroom, which is rendered in grayscale save for the saturated red of the shoes and rug. The reader is able to see a window seat with a pillow embroidered with "faith," the footboard of the bed, and a partial view of a door. The lower panel offers a close-up 
perspective of the red shoes, which are centered in the composition. The text accompanying the lower panel is that in which the narrator considers her name, "I have another name [...]. I keep the knowledge of this name like something hidden, some treasure I'll come back to dig up, one day. I think of this name as buried" (Atwood and Nault 2019: II Shopping, n.p.). In Nault's portrayal, the rug resembles a target, or, given the placement of the shoes at the edge, a hole to jump or fall into, or, further, given the juxtaposed text, a future excavation site.

The Handmaid's shoes are a continued motif throughout the adaptation, and provide the focus of several panels - the narrator walking doubled with her shopping partner, under the stall door in the Red Center bathroom, dressing in her bedroom, walking through Serena's garden, shoes like hers dangling from the gallows. The rug also comes to symbolize the narrator and her personal safety. The concluding scene, in which the Eyes come for Offred, includes a panel in which a guard's boot steps onto the round red rug; yet, a few pages later, this potential threat is revealed as a potential opportunity. The novel's opening image is bookended by that at the "tale's" close-a full, white page, the top half of which depicts the narrator's billowing skirt and single shoe-shod foot as she runs toward the future, "And so I step up, into the darkness within; or else the light" (Atwood and Nault 2019: XV Night, n.p.). The absence of the rug, here, reinforces the idea that Offred has "stepped up," or "stepped into."

As in the case of other adaptations, the graphic novel explores the tension between the Handmaids' uniformity and individuality, both thematically and compositionally. Nault's achievement is perhaps best seen in a series of panels devoted to the narrator's daily meetings with her shopping partner, Ofglen. Atwood's first description of this meeting reinforces the manner by which Gilead codes Handmaids as identical and shows, also, that they remain individual to each other: "A shape, red with white wings around the face, a shape like mine, a nondescript woman in red carrying a basket, comes along the brick sidewalk towards me. She reaches me and we peer at each other's faces, looking down the white tunnels of cloth that enclose us. She is the right one" (Atwood 1985: 28-29). Nault adapts these meetings in several half-page panels spaced through the novel, each of which includes an inset half circle, which is divided into four rows, each depicting a distinct stage in the meeting: one Handmaid waiting alone, another's approach and their exchange of greeting, the two standing together, two walking off. The background behind the half circle depicts 
the houses of two Commanders. The state of being the "right one" comes to mean later when the narrator realizes that she is meeting the "wrong" one. Toward the end of the novel, the narrator waits at the corner for the partner she has come to know as Ofglen. Nault renders this meeting compositionally in the same manner as the previous two meetings. The accompanying text reads: "I notice nothing at first. Then, as she comes nearer, I think that there must be something wrong with her. She looks wrong" (Atwood and Nault 2019: XIV Salvaging, n.p.). At this moment, the narrator realizes that the woman she has come to understand as Ofglen is no longer Ofglen. This name has come to signify a new body, one that Atwood's narrator comes to understand through differential features: "She is altered in some indefinable way [...]. She isn't Ofglen. She's the same height, but thinner, and her face is beige, not pink" (Atwood 1985: 294). Nault establishes Offred's realization through visual markers that likewise become evident through comparison. Whereas in the previous scenes, the figure approaching from the left of the frame is slightly shorter than the figure waiting toward the center of the frame, in this last meeting the approaching figure is slightly taller than the figure waiting. In visually presenting this meeting as the same as those before it, Nault creates a telling rift between the visual and worded cues and again reinforces that tension between what is visible or invisible, what is observed, and what is understood.

\subsection{Motion-Based Transfer}

As we have seen, the transfer of iconography in print-based visual adaptations of The Handmaid's Tale tends to reinforce the Handmaid uniform as a shorthand signifier for a range of meanings, and does so in ways that foreground unique medial and modal aspects. I will now turn to an examination of audiovisual, motion-based adaptations on stage and film. The transfer of iconography from a verbal, written media product to an audiovisual, motion-based one involves activities similar to those utilized in print-based visual adaptation in that worded descriptions and narrative voice are conceptualized in new ways, but audiovisual, motion-based adaptations likewise bring in additional considerations, among them gesture, movement, three-dimensionality versus two-dimensionality, live or recorded performance, live or recorded speech and music. For example, The Handmaid's Tale as conveyed through ballet poses a medial experience unique from an operatic version, though both communicate broadly 
through set, sound, movement, and gesture. Similarly, a one-woman theatrical performance of The Handmaid's Tale and a television series both transfer theme, iconography, and other elements from Atwood's novel and other adaptations, yet each poses unique challenges, among them pacing, character empathy, dialogue construction, and set design. My goal in what follows is not to provide an exhaustive examination of each modality, but, rather, to highlight the manner by which balletic, operatic, theatrical, filmic, and televisual adaptations of The Handmaid's Tale interpret iconography of the Handmaid uniform, and, in so doing, demonstrate the flexibility of the iconography and the manner by which it might be bent to align with a specific modality.

As has been the case for print-based adaptations, the transfer of iconography from one media product to another in audiovisual, motion-based adaptations has come to rest most visibly in the uniform. As the uniform transfers from motion-based adaptation to motion-based adaptation, it is adapted to meet the requirements of different modalities. Because the uniform described by Atwood is too restrictive for dance, in adapting The Handmaid's Tale to ballet, costumer designer Liz Vandal reimagined the Handmaid uniform for choreographer Lila York's "dance drama," which premiered with Canada's Royal Winnipeg Ballet in October 2013, as a red tunic with a triangle-shaped yoke that covers the head, and is open at the sides and fitted over a gray leotard. The bonnet and white wings are reimagined as a structured, pyramid-shaped headpiece fitted to the back of the dancer's head. While a technical necessity for this modality, the increased mobility and unrestricted vision of this uniform create a version of the Handmaid distinct from that offered by Atwood, and many other adaptations. Within Gilead's stratified society, mobility is linked to power, and each group's uniform allows a degree of mobility and visibility appropriate to their station. As Atwood's narrator explains, the Handmaid's uniform limits perception and vision: "Given our wings, our blinkers, it's hard to look up, hard to get the full view, of the sky, of anything. But we can do it, a little at a time, a quick move of the head, up and down, to the side and back. We have learned to see the world in gasps" (1985: 40). In tokenizing a fundamental feature of the costume, the ballet impacts the audience's sense of how the iconography functions within the society.

The conditions of live performance may have informed also the decision of the Boston Lyric Opera adaptation (2019), directed by Anne Bogart, and conducted by David Angus, to opt for the white bonnet, but not the wings. ${ }^{6}$ The wings would likely impact the performers' hearing 
and ability to communicate with each other on stage. Yet, as with the balletic adaptation, the visibility of the Handmaids' faces to audiences both within and outside the diegesis, and Handmaids' own unobstructed vision, impacts audiences' understanding of the role of the Handmaid uniform within Gileadean social structures. In other ways, though, the opera overtly aligns itself with established iconography of the uniform by including in the program a sketch for the Handmaids' costume by James Schuette, who also designed the sets, juxtaposed against an image of Marcellino's cover design for the Jonathan Cape edition. ${ }^{7}$

The one-woman The Handmaid's Tale stage adaptation written by playwright Joe Stollenwerk's script, directed by Brian Isaac Phillips, and performed in 2015 at the Know Theatre of Cincinnati, featuring Corinne Mohlenhoff as Offred, likewise omits the white wings, though, as the play unfolds within a single, private setting, the absence is not as pronounced. Additionally, given that the performance (including communication of character, story, narrative tension, and conflict) rests on the nuances of Mohlenhoff's delivery, the costume decision is understandable. In Noelle Wedig's costume design, the bonnet fits over a cowl-like garment that conceals the Handmaid's hair and head. This layering of garments coupled with Andrew J. Hungerford's strategic lighting design, which utilizes high- and low-contrast effects to reflect and craft emotional and environmental mood, creates a Handmaid who, though literally visible to the audience, comes through as metaphorically veiled. Zack Hatfield, reviewing the play for The News Record, likewise comments on the relationship between costuming and lighting in this production, calling Wedig's interpretation of the Handmaid costume, "a visual marvel, encapsulating the appropriate shades of paranoia and violence," and commenting that Hungerford's lighting "creates a tonal dissonance vital to understanding the complex psyche of Mohlenhoff's role" (Hatfield 2015).

Implications for performance and reception likewise inform how film and television adaptations interpret the Handmaid uniform. Colleen Atwood's take on the iconic uniform for the 1990 film adaptation directed by Volker Schlöndorff and starring Natasha Richardson is much more streamlined than other iterations. Handmaids in this version wear only a sheer, red head scarf in public, and occasionally a red veil. Handmaids' faces are visible, and they remain distinguishable from one another, as a result. The decision to avoid a more obtrusive head covering may have come from a fear of blocking the audience's view of actors' faces. If the poster advertising the film, which features lead Natasha Richardson, 
ostensibly unclothed save for the red garment she holds against her body, is any indication, this film seems much less concerned with highlighting the Handmaids' invisibility within Gilead than in highlighting Richardson's star qualities. By contrast, for the Hulu series created by Bruce Miller, which aired on April 26, 2017, costume designer Ane Crabtree, understanding the aesthetic and symbolic impact of the full, white wings, persuaded the show's developer to use them instead of less obtrusive headscarves (Chuba 2018). In the third season, in particular, the series begins to exploit the headpiece as a device of both invisibility and visibility. Episode 2, for example, opens with a scene of June/Ofjoseph (formerly Offred) waiting for her shopping partner, and watching other Handmaids pass her on the street. The camera adopts a subjective perspective from "behind" the white wings, allowing viewers to see the scene as she does, as if through a tunnel. Once within the grocery, however, June/Ofjoseph uses the privacy provided by the wings to exchange information with Alma/Ofrobert, a Handmaid involved in helping to organize the resistance.

The motion-based adaptations reiterate the significance of the iconography of the red cloak and white bonnet in ways that highlight features of their specific modalities. Thus, the highly stylized uniform adopted by the ballet supports both the aesthetic characteristics and physical necessities of the medium - the uniform is visible, but downplayed to foreground the physicality of dance. In comparison, the Hulu series can utilize more restrictive uniforms because the handheld cameras can compensate for actors' restricted mobility.

\subsection{Transfer and Networks}

The popularity of the Hulu series and the popular media's depictions of the series as a mirror to the political climate have contributed, no doubt, to the "real world" upswing in Handmaid iconography and what we might think of as "embodied" adaptation. Since spring 2017, individuals have donned Handmaid cloaks and white bonnets at numerous protests globally, mostly related to women's reproductive rights and real and threatened erosions of other freedoms, among them the NARAL Pro-Choice protests in Texas, protests against the abortion ban in Ireland, and against Brett Kavanaugh's 2018 United States Supreme Court nomination. As Guardian writer Arielle Bernstein notes, "The image of the red robed and white bonneted women [...] has become as celebrated as Rosie the 
Riveter" (2018). Alex Yarde, writing for The Good Men Project, compares "the unmistakable iconography of the red bonnet as a universal symbol of oppression," to "the white worn in the Suffrage Movement at the turn of the last century" (2019). This pattern of reading the Handmaid "in context" brings us to an important question: what does the Handmaid uniform symbolize?

To answer this question, I return to the examples with which this essay began and the questions they raise: How did a line of red trees come to make a political statement? How did a group of women in red cloaks come to illustrate a threat to scientific research? How did a red cloak and white bonnet become a site of sexual pleasure? Each of these examples comes to "mean" at the point of transfer, or, borrowing from Elleström's communication model, in the "intermediate stage" between one place and another, "that makes the transfer possible" (2020: 10). That is, each comes to mean at the point when the perceiver recognizes the "thing" as not the thing. For example, the trees in the colonnade are simply topiaries, three-dimensional static structures composed of faux cranberry branches. Set within the larger cultural moment, the trees are still seen as trees but also, satirically, as not trees, as Handmaids. In transferring the iconography of the Handmaid from the Hulu series to the holiday display, the edited photograph discloses a semiotic message that conceals the materiality of the topiary. The materiality continues to exist (i.e., the topiary continues to exist as a holiday decoration), but, within the context of the photograph, the tree's semiotic potential dominates in the transfer of the message to the perceiver. The political efficacy of the protesters dressed as Handmaids comes in the recognition that they are not Handmaids, but, rather, are evoking the status of Handmaid to prove a point. Were the women actually Handmaids, the act of wearing the uniform would not constitute protest. Likewise, in the example of the "Brave Red Maiden" costume, the iconography of the Handmaid transfers to the person wearing the costume. A pleasure in the costume is recognizing the lover as both Handmaid and not Handmaid. In each example, the transfer of iconography exposes the border between the thing and not the thing. The precision of the semiotic sign is not as important as the sign's broader connotations, which are understood through the perceiver's recourse to collateral experience.

Perceivers' collateral experience, which, in the case of these examples, takes shape from a larger adaptation network, might include familiarity with Handmaid iconography through experiences with one or more of the 
numerous print- and motion-based adaptations, visual publicity for the Hulu series, or accounts of protesters in the news. The experience allows perceivers to perceive the message in the transfer, thus enabling them to decode the representation - as a political or erotic, for example-within the context of The Handmaid's Tale. Perceivers' experiences with varied messaging allow them to decode the line of red trees, or the group of women in red cloaks, or the costume denotatively, and perceivers' recourse to the intermedial adaptation network allows them similarly to decode these examples connotatively.

What can The Handmaid's Tale's adaptation network tell us about intermediality in general? As Rajewsky, Elleström, and others have demonstrated, the so-called borders between media and modalities are largely contrived and perceptual. Recognizing such borders as constructed, however, is not in conflict with a recognition of their usefulness or a curiosity related to their areas of porosity - the shifting points of contact generated through processes of adaptation. Perceivers' collateral experiences shape their decoding of icons, as does the generalized collateral experience generated by the repetition of specific iconography through an adaptation network. Elleström's and Rajewsky's proposals that intermediality be conceptualized as a meeting of "border zones" remain a productive way of thinking about such relationships (Elleström 2010; Rajewsky 2010). As Rajewsky explains, borders can be understood as sites of possibility, "as enabling structures, as spaces in which we can test and experiment with a plethora of different strategies" (2010: 65). Adaptation is the enabling structure that makes the transfer of iconography between media products possible. Much like Atwood's narrator, who serves as an intermediary between books and discs, but who also redirects that transfer to other, unanticipated points of communication, adaptation illuminates areas of porosity between media and media products, further erodes notions of impermeable divisions between media, and enables understanding of broadening intermedial networks.

\section{Notes}

1. Yandy pulled this costume, also dubbed the "sexy Handmaid," from the website after negative public response. See Elassar and Muaddi (2019) and Vagianos (2019).

2. David Lyman, for example, commenting on Strollenwerk's 2015 play states that "There was a time $[\ldots]$ when the idea of suspending or abridging 
Constitutional rights was inconceivable. Yet in the wake of the $9 / 11$ attacks, we saw just how natural it felt for citizens and governments to overreact in the name of national security" (Lyman 2015). Deborah Dundas, who interviewed Renée Nault for The Toronto Star, notes that delays in developing the graphic novel adaptation resulted in a keen alignment of the book's thematics and current politics: "its dystopian slant echoes many of the issues facing a Donald Trump America-eroding women's rights, the rise of religious fundamentalism" (Dundas 2019).

3. Rajewsky quotes from Werner Wolf (1999: 40-41).

4. I recognize that metaphors of movement are contested in adaptation studies, as they elide relationships between form and content. I adopt the metaphor of transfer deliberately here in recognition of its significance in The Handmaid's Tale. "Transfer" is also not without precedent in discussions of adaptation and intermediality. Lars Elleström uses this metaphor effectively in presenting what he identifies as "ten border zones of adaptation" (2017: 513).

5. When asked about her inspiration for the Handmaids' uniforms, Margaret Atwood cites the stick-brandishing woman on containers of Old Dutch Cleanser-a figure who "chases dirt" and promises "healthful cleanliness," and who terrified Atwood as a child. Atwood's adaptation of this image rests largely on the headpiece that hides the figure's face from view (Flock 2017).

6. The Handmaid's Tale opera was first performed in 2000 by the Danish Royal Opera in Copenhagen, conducted by Michael Schonwandt. In 2003, the English National Opera and the Minnesota Opera both reprised the program. In 2004, the Danish Royal Opera performed the program in Toronto.

7. That this production is staged in the Ray Lavietes Pavilion-the Harvardowned athletic arena thought to be the inspiration for the building that houses Atwood's Red Center-with the action unfolding on what would be the gymnasium floor, points to an attempt to foster an immersive experience. As Lucy Caplan notes in an essay included in the production program: "rather than just reading about the hypothetical possibility of this space as the Red Center, you experience that transmogrification in real time and among other people. It is happening here" (Caplan 2019).

\section{REFERENCES}

Anderson, Porter. 2017. Part 2: 'Light and shadow'-Anna, Elena Balbusso on Margaret Atwood's 'Handmaid's Tale.' Publishing Perspectives, 28 April. https://publishingperspectives.com/2017/04/italy-balbusso-twins-Handmaids-tale-interview-part-2/. Accessed 15 July 2019.

Atwood, Margaret. 1985. The Handmaid's Tale. London: Jonathan Cape. 
2012. The Handmaid's Tale. Illustrated by Anna and Elena Balbusso. London: The Folio Society.

Atwood, Margaret, and Renée Nault. 2019. The Handmaid's Tale: The Graphic Novel. New York: Nan A. Talese/Doubleday.

Bernstein, Arielle. 2018. The Future Isn't Female Enough: The Problematic Feminism of The Handmaid's Tale. The Guardian, 8 May. https://www.theguardian.com/tv-and-radio/2018/may/08/the-future-isnt-female-enoughthe-problematic-feminism-of-the-handmaids-tale. Accessed 13 June 2019.

Caplan, Lucy. 2019. Opera in the Golden Age of the Feminist Dystopia. The Handmaid's Tale Program Book, Boston Lyric Opera, May 5-12, 2019. https://issuu.com/bostonlyricopera/docs/blo_thtprog_web2. Accessed 01 July 2019.

Chuba, Kristen. 2018. 'Handmaid's Tale' Costume Designer on Offred's Look as a Political Statement: 'It's Throttling in a Beautiful Way.' Variety, 10 June. https://variety.com/2018/tv/news/handmaids-tale-costume-designer-produced-by-conference-1202838943/. Accessed 8 June 2019.

Deliee, Madeleine. 2019. How I made It: Renée Nault, Illustrator of 'The Handmaid's Tale' Graphic Novel. Shondaland, 15 March. https://www.shondaland.com/inspire/books/a26825266/Handmaids-tale-graphic-novelrenee-nault-illustrator/. Accessed 1 June 2019.

Dundas, Deborah. 2019. The Handmaid's Tale Graphic Novel Lets Illustrator Renee Nault Find Room for Her Own Ideas. Toronto Star, 21 March. https:// www.thestar.com/entertainment/books/2019/03/21/the-Handmaids-talegraphic-novel-lets-illustrator-renee-nault-find-room-for-her-own-ideas.html. Accessed 1 June 2019.

Elassar, Alaa, and Nadeem Muaddi. 2019. Retailer Drops Sexy 'Handmaid's Tale' Costume Following Outcry. Cnn.com, 21 September. https://www.cnn. com/2018/09/21/us/Handmaids-tale-halloween-costume-trnd/index. html. Accessed 26 August 2019.

Elleström, Lars. 2010. The Modalities of Media: A Model for Understanding Intermedial Relations. In Media Borders, Multimodality and Intermediality, ed. Lars Elleström, 11-48. Basingstoke: Palgrave Macmillan.

- 2017. Adaptation and Intermediality. In The Oxford Handbook of Adaptation Studies, ed. Thomas Leitch, 509-526. Oxford: Oxford University Press.

- 2020. The Modalities of Media II: An Expanded Model for Understanding Intermedial Relations. In Beyond Media Borders: Intermedial Relations among Multimodal Media, Volume 1, ed. Lars Elleström, 3-91. Basingstoke: Palgrave Macmillan.

Flock, Elizabeth. 2017. How Margaret Atwood Dreamed Up the Costumes in 'The Handmaid's Tale.' PBS.org, 25 April. https://www.pbs.org/newshour/ 
arts/how-margaret-atwood-dreamed-up-the-costumes-in-the-handmaids-talepremiere-hulu. Accessed 3 September 2019.

Gupta, Prachi. 2018. I Don't Know How to Feel About this Sexy Handmaiden Costume. Jezebel, 20 September. https://jezebel. com/i-dont-know-how-to-feel-about-this-sexy-Handmaidencost-1829204492. Accessed 2 April 2019.

Hatfield, Zack. 2015. Theater Review: 'The Handmaid's Tale.' The News Record, 25 January. https://www.newsrecord.org/arts_and_entertainment/theaterreview-the-handmaid-s-tale/article_9033d244-a4e 0 - l le 4a685-3fbb824e0185.html. Accessed 2 April 2019.

Lyman, David. 2015. 'Handmaid's Tale' Offers Extreme View of Future. The Cincinnati Enquirer, 24 January. https://www.cincinnati.com/story/entertainment/theater $/ 2015 / 01 / 24 /$ Handmaid-tale-know-theaterreview/22271029/. Accessed l August 2019.

Neergaard, Lauran, Malcolm Ritter, and Ricardo Alonso-Zaldivar. 2019. Scientists Feel Chill of Crackdown on Research. Savannah Morning News, 9 June.

Newell, Kate. 2017. Expanding Adaptation Networks: From Illustration to Novelization. Basingstoke: Palgrave Macmillan.

Rajewsky, Irina O. 2010. Border Talks: The Problematic Status of Media Borders in the Current Debate About Intermediality. In Media Borders, Multimodality and Intermediality, ed. Lars Elleström, 51-68. Basingstoke: Palgrave Macmillan.

Romney, Rebecca. 2017. Thirty Years of Cover Designs for The Handmaid's Tale. 13 March. https://rebeccaromney.wordpress.com/2017/03/13/coverdesigns-Handmaids-tale/. Accessed l March 2019.

The Handmaid's Tale. 1990. Directed by Volker Schlöndorff. Cinecom Pictures.

2017. Created by Bruce Miller. Hulu and MGM Television.

2019. The Folio Society. https://www.foliosociety.com/usa/the-Handmaid-s-tale.html. Accessed 19 August 2019.

Transfer. 2019. Lexico. https://www.lexico.com/en/definition/transfer. Accessed 2 April 2019.

Vagianos, Alanna. 2019. Yes, Yandy Really Made a 'Sexy' 'Handmaid's Tale' Halloween Costume: And, No, It Didn't Go Over Well. HuffPost, 21 September. https://www.huffpost.com/entry/yes-yandy-really-made-a-sexyhandmaids-tale-halloween-costume_n_5ba4flafe4b0181540dc4c08. Accessed 26 August 2019.

Wolf, Werner. 1999. The Musicalization of Fiction: A Study in the Theory and History of Intermediality. Amsterdam: Rodopi. 
Yarde, Alex. 2019. Book Review: The Handmaid's Tale (The Graphic Novel) by Margaret Atwood. Art \& Adaptation by Renee Nault, Nan A. Tales/Doubleday, 26 March. https://goodmenproject.com/featured-content/456808-xela/. Accessed 2 April 2019.

Zutter, Natalie. 2017. Rereading The Handmaid's Tale: The Legacy of Margaret Atwood and Offred. Tor.Com, 13 April. https://www.tor.com/2017/04/13/ rereading-the-Handmaids-tale-the-legacy-of-margaret-atwood-and-offred/. Accessed 2 April 2019.

Open Access This chapter is licensed under the terms of the Creative Commons Attribution 4.0 International License (http://creativecommons.org/licenses/ by $/ 4.0 /$ ), which permits use, sharing, adaptation, distribution and reproduction in any medium or format, as long as you give appropriate credit to the original author(s) and the source, provide a link to the Creative Commons licence and indicate if changes were made.

The images or other third party material in this chapter are included in the chapter's Creative Commons licence, unless indicated otherwise in a credit line to the material. If material is not included in the chapter's Creative Commons licence and your intended use is not permitted by statutory regulation or exceeds the permitted use, you will need to obtain permission directly from the copyright holder.

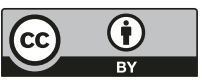

